\title{
ASSESSMENT OF THE PRODUCTION VARIABLES ON THE PELLETIZATION PROPERTIES OF MICROCRYSTALLINE CELLULOSE II (MCCII)
}

\author{
JOHN ROJAS*, DAVID CORREA \\ Department of Pharmacy, School of Pharmaceutical and Food Sciences, University of Antioquia, Medellin, Columbia \\ Email: jrojasca@gmail.com
}

Received: 08 Jun 2017 Revised and Accepted: 31 Aug 2017

\begin{abstract}
Objective: To study microcrystalline cellulose II (MCCII) as new pelletization aid using the extrusion/spheronization technology.

Methods: The effect of the spheronization rate and spheronization time was assessed by a response surface design. The shape descriptors and physical properties of pellets were taken as response variables. Approximately, $30 \mathrm{~g}$ of MCCII were hydrated, passed through a \# 20 mesh sieve and spheronizated at frequencies of 6,9 and $12 \mathrm{~Hz}$ and residence times of 15, 240 and $480 \mathrm{~s}$ in 9 experimental runs. In a separate experimental set, moisture levels of 25, 50, 75, 100 and $125 \%$ were employed at the optimal operating conditions of $6 \mathrm{~Hz}$ and $480 \mathrm{~s}$. A microscopy analysis was used to evaluate the shape descriptors. Pellets properties such as compressibility, friability, porosity, strength, flow rate and mass were also evaluated.
\end{abstract}

Results: Pellets having a small size and a high value of shape descriptors related to morphology were obtained employing a spheronization rate and spheronization time of $6 \mathrm{~Hz}$ and $480 \mathrm{~s}$ and $100 \%$ wetting level. The spheronization time increased pellet densification but decreased the total porosity. Pellet mass was also favoured by using high spheronization rates. A high moisture level $(>100 \%)$ rendered pellets having a large size, mass, low porosity and good yield. Conversely, pellet size decreased as sample load increased, whereas porosity and compressibility increased as sample load augmented.

Conclusion: MCCII offers the potential for use as an alternative pelletization agent rendering pellets having a good flowability, high mechanical strength and low friability at the optimal operational conditions.

Keywords: Extrusion-spheronization, Spheronization rate, Spheronization time, microcrystalline cellulose II

(C) 2017 The Authors. Published by Innovare Academic Sciences Pvt Ltd. This is an open access article under the CC BY license (http://creativecommons.org/licenses/by/4.0/) DOI: http://dx.doi.org/10.22159/ijpps.2017v9i10.20580

\section{INTRODUCTION}

Pelletization is a technique used to convert a mixture of fine powders of bulk drugs and excipients into spherical or semispherical pellets with a mean size between 0.5 and $2 \mathrm{~mm}$ [1]. This technique allows for the incorporation of high drug loads rendering pellets having a high density, low friability, narrow and uniform size distribution, and good flowability. Pellets are generally intended for oral administration [2]. They are less affected by the gastric emptying rate and intestinal transit time. Pellets render a low risk of side effects by preventing dose dumping. Further, pellets having similar densities and particle sizes show a lesser tendency towards segregation and improve content uniformity [3].

Pellets disperse freely in the gastrointestinal tract, thereby maximizing bioavailability and reducing the intra-and interindividual variation in plasma drug levels. Thus, the safety and efficacy of a drug is improved. Pellets are able to keep a mixture of incompatible drugs with different release profiles in the same dosage form. Therefore, they are adaptable since in a single formulation having a unique process several doses can be formulated to control the release profile and pharmacokinetic parameters. They are also easy to pack due to the uniformity of the capsule-filling process. Nevertheless, pellet production is expensive since it requires highly specialized and trained personnel who carefully control the production process. For instance, the wetting and spheronization processes are critical variables since overwetting can easily occur. The general process involves extrusion of a wet mass followed by subjection to a centrifugal movement in a spheronization chamber. In this process, agglomerates are formed which are then rounded and densified into a spherical shape. Therefore, size, density and shape of the resulting pellets are influenced by the operational conditions [4].

Only few excipients can be used for the extrusion-spheronization process due to the strict requirements they must fulfill. First, they should form a cohesive plastic mass upon wetting. The wet mass should be mechanically strong, and brittle enough to be broken down into short lengths in the spheronizer [5]. Microcrystalline cellulose I (MCCI) has been the traditional excipient for extrusionspheronization and its rheological properties are suitable for this process. MCCI can absorb large amounts of water favoring the formation of microgranules having the suitable plasticity, rheology, and cohesive properties to produce beads [6]. The pelletization properties are also affected by the chemical composition, degree of polymerization, degree of crystallinity, moisture content and particle morphology [7].

MCCII is a new cellulosic allomorph that possesses a very high internal porosity, amorphicity and a large surface area because of the antiparallel arrangement of its chains. These phenomena provide a high absorption and moisture retaining properties. The retained water molecules could act as a lubricant during extrusion, and control the pellet shape during spheronization [8]. The aim of this study was to evaluate the impact of spheronization frequency and time, wetting level and sample load on the morphology and particle properties of the resulting MCCII pellets employing a response surface design.

\section{MATERIALS AND METHODS}

Production of MCCII pellets using a response surface design

MCCII was obtained from cotton linters as reported previously [8]. Approximately, $30 \mathrm{~g}$ of MCCII was wetted with $30 \mathrm{ml}$ of distilled water and passed through a \#20 mesh sieve $(841 \mu \mathrm{m}$ size $)$ with a force $\leq 11.2 \mathrm{~N} / \mathrm{cm}^{2}$ measured with a load cell (LCGD-10K, Omega Engineering, Inc., Stamford, CT). The extruded thus obtained was put in the spheronizer chamber (Model 1LA70-4YA60, Siemens), which was operated at spheronization rates of 6,9 and $12 \mathrm{~Hz}$ and spheronization times of 15,240 and 480 s to produce beads, which were then oven-dried at $60{ }^{\circ} \mathrm{C}$ until the moisture content was less 
than $10 \%$. Then, beads were fractionated and particles with diameters larger than $250 \mu \mathrm{m}$ were only utilized. The effect of wetting was studied on a separate experimental setting at the optimal operational conditions of $6 \mathrm{~Hz}$ and 480s and wetting levels of $25,50,75,100$ and $125 \%$ (w/w) on a dry basis. Further, the effect of the MCCII load on the pellet properties was tested at the optimal conditions, $100 \%$ wetting level and loads of $30,50,100$ and $150 \mathrm{~g}$.

\section{Pellet properties}

The moisture content was determined using $\sim 1 \mathrm{~g}$ of sample on an infrared moisture balance (Scout Pro, OHAUS Corp., Parsippany, NJ) at $100{ }^{\circ} \mathrm{C}$ for $10 \mathrm{~min}$ (Scout Pro, OHAUS Corp., Parsippany, NJ). Flow rate was determined using $\sim 15 \mathrm{~g}$ of sample passed through a glass funnel with a neck diameter of $13 \mathrm{~mm}$ and subsequently, the measurement of the flow time was taken. The ratio between mass and the respective time was taken as the flow rate [9].

Friability is the property related to the pellet ability to withstand shock and abrasion without fragmentation. It measures the pellet tendency to flake off during handling. This test was performed on $\sim 6.5 \mathrm{~g}$ of the sample previously retained on a \# 60 mesh. A friabilator (FAB-25 1,351,130, Logan) operated at $25 \mathrm{rpm}$ for $4 \mathrm{~min}$ was employed. At the end of the test, only the fraction retained on the \# 60 mesh sieve was quantified.

Bulk density ( $\rho_{\text {bulk }}$ ) was obtained directly from the ratio of $\sim 3 \mathrm{~g}$ powder and its volume measured in $10 \mathrm{ml}$ graduated cylinder. Tap density $\left(\rho_{\text {tap }}\right)$ was determined using an Autotap ${ }^{\circledR}$ density analyzer (AT2, Quantachrome Instruments, Boynton Beach) measuring the volume after 300 taps. Volume data for each cycle were fitted to the Kawakita compressibility model.

A Helium displacement micropicnometer (AccuPyc II 1340, Micromeritics, USA) was employed to obtain the pellets true density and porosity. Samples were oven-dried at $60{ }^{\circ} \mathrm{C}$ for $48 \mathrm{~h}$, followed by purging with Helium for at least $15 \mathrm{~min}$, before each measurement. True density was calculated by dividing the mass of the material by the true volume. Porosity $(\varepsilon)$ of the powder was determined from the true density measurements as reported previously [9].

\section{Shape and size descriptors}

The morphology analysis and the particle size distribution were obtained by microscopy analysis. Optical micro pictures containing at least 650 particles were taken using an optical stereoscope (BM 180P, Boeco, Hamburg, Germany) at a 50x magnification coupled with a Fuji digital camera (FinePix S9000, Fujifilm, Tokio, Japan). The digital analysis of the micropictures was done using the Image J software (v. 1.46r, NIH, Bethesda, MD). Particle size was obtained directly from the lognormal plots of the resulting distributions. The expressions used to calculate the shape descriptors are shown as follows:

$$
\begin{aligned}
& \text { Circularity }=\left(\frac{4 \pi * \text { Area }^{2}}{\text { perimeter }^{2}}\right) \\
& \text { Sphericity (roundness) }=\left(\frac{4 * \text { Area }}{\pi * \text { Feretdiameter }^{2}}\right) \\
& \text { Aspectratio }=\left(\frac{\text { width }}{\text { lentgh }}\right) \text {. } \\
& \text { Solidity }=\frac{\text { Area }}{\text { Convexarea }}
\end{aligned}
$$

\section{RESULTS AND DISCUSSION}

\section{Effect of operational conditions on pellet properties}

The micro pictures of the pellets are depicted in fig. 1. During the wet massing process, the MCCII fibers coalesced and formed larger particles which were then shaped once they passed through the screen orifices. These, in turn, were molded in the spheronizer which cut-off and rounded-off the sharply and roughly surfaces.

The rotating plate operating at the largest rate $(12 \mathrm{~Hz})$ and residence times larger than 120 s produced a denser and smoother pellet surface due to the combined action of the centrifugal force created by plate rotation, the vertical force formed by collision, and the gravitational force allowing for the formation of a torroidal or twisted rope motion having an spiral pattern. As a result, large frequencies and residence times generated more frictional and rotational forces where the initial small, oblong and granular particles experienced growth, folding and edge rounding which was subsequently shaped into dumb bells. These dumb bells were then twisted, broken, rounded and transformed into spherical or semispherical beads. These findings are in agreement with previous studies conducted by other researchers [10]. Further, by employing a residence time of only $30 \mathrm{~s}$ and the $30 \mathrm{~cm}$-diameter rough cross-hatch plate the resulting pellets had a predominantly small size, oblong shape and rougher surface. Conversely, reports indicate that spherical pellets with the smoother surface are obtained only using high rotor speeds [11].
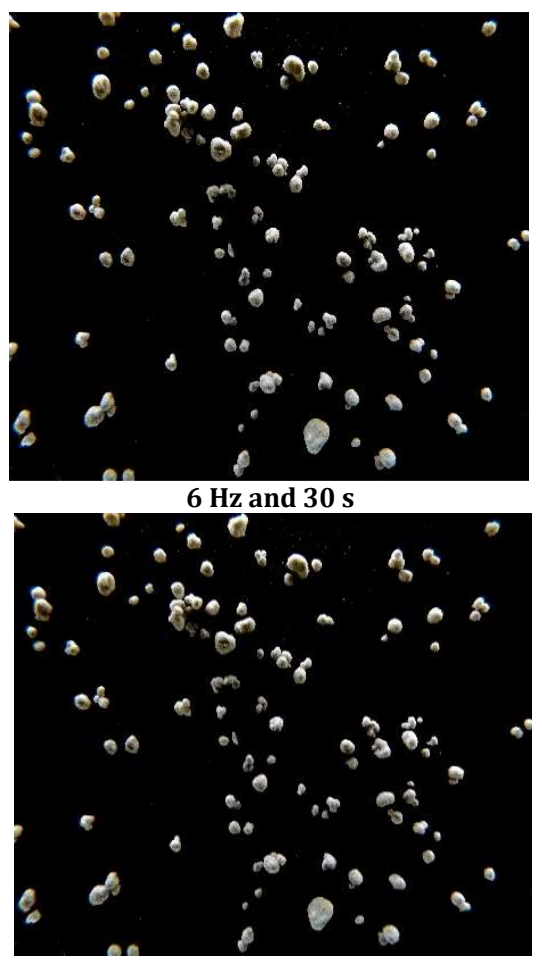

$9 \mathrm{~Hz}$ and $30 \mathrm{~s}$

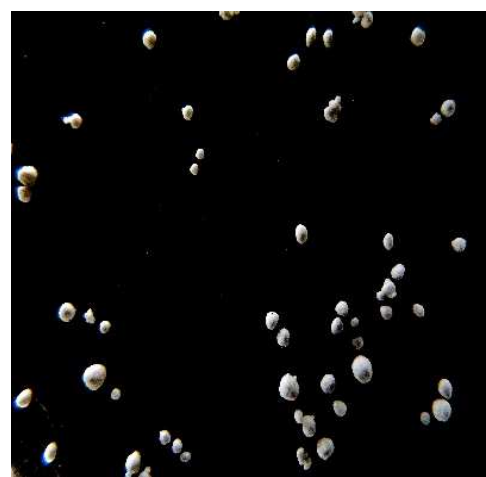

$6 \mathrm{~Hz}$ and $120 \mathrm{~s}$

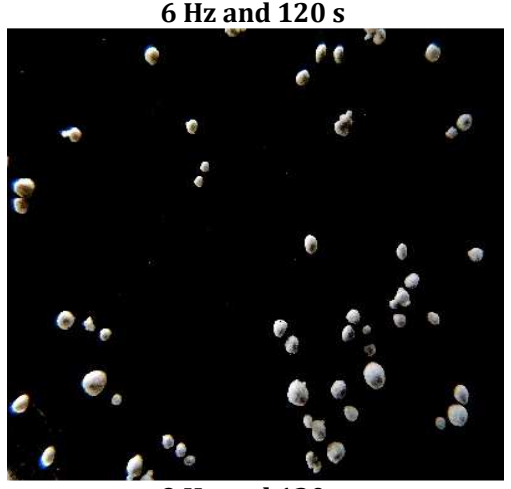

$9 \mathrm{~Hz}$ and $120 \mathrm{~s}$

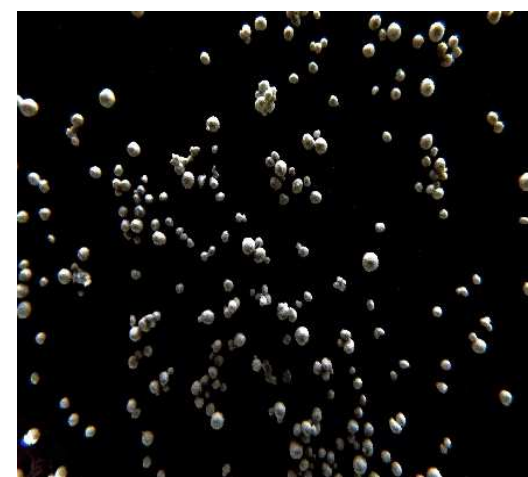

$6 \mathrm{~Hz}$ and $480 \mathrm{~s}$

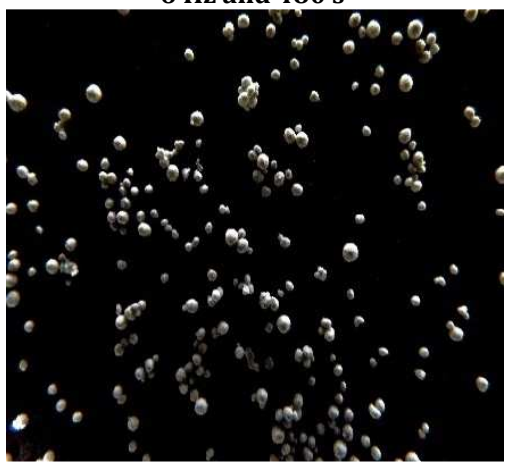

$9 \mathrm{~Hz}$ and $480 \mathrm{~s}$ 

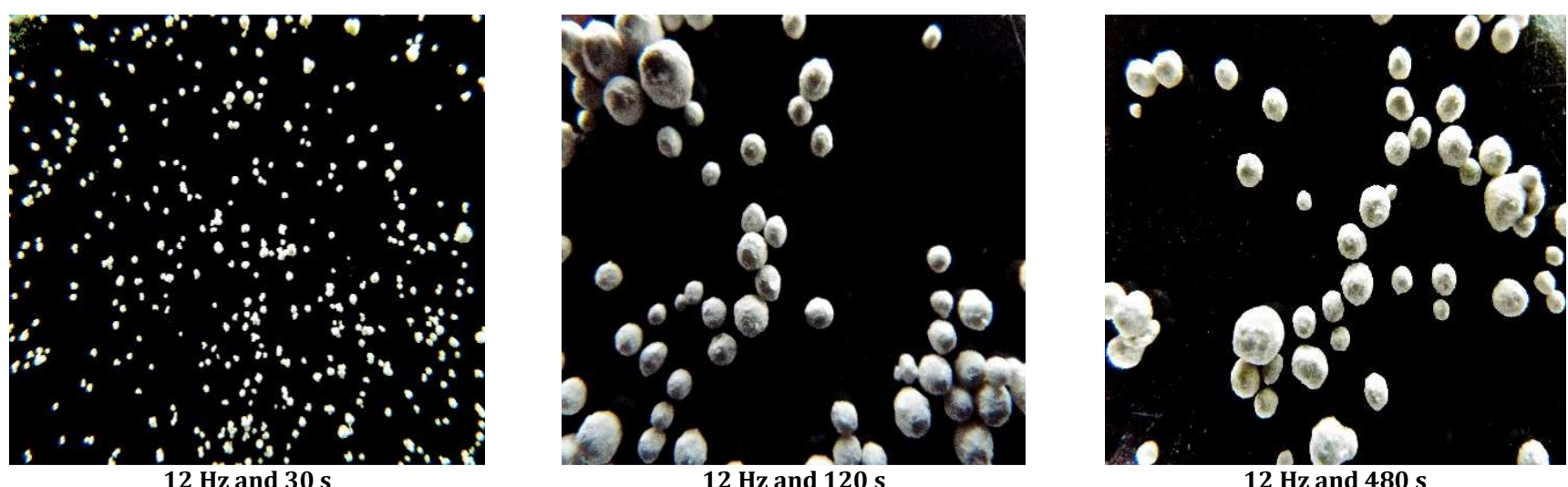

Fig. 1: Micro pictures of beads produced under different processing conditions and $100 \%$ wetting level

The physical property of the beads is listed on table 1 . The spheronization platform usually renders bead sizes of about 1000 $\mu \mathrm{m}$. In this case, by using a \#20 screen sieves the size of the resulting beads ranged from 0.97 to $1.42 \mathrm{~mm}$. Previous results conducted on MCCI rendered sizes from 1.2 to $4 \mathrm{~mm}$ using a \#14 mesh [6]. Thus, by using a large screen size during the granulation step, the size of the resulting beads is also increased. Further, particle size, area and perimeter tend to increase with residence time except for runs conducted at 480s which showed small values, probably due to the loss of moisture and the required plasticity for pellet growth. Further, runs conducted at high speeds showed a wider variability in particle size due to the wider particle size distribution. Thus, it is more convenient to employ low spheronization rates to obtain beads with diameters smaller than $1 \mathrm{~mm}$.

The spherical morphology and particle size played a major role on densification and porosity. As a consequence, bead densification increased slightly with increasing spheronization time and rates.
This occurrence was reflected on the resulting porosity which in turn, decreased with large spheronization times and rates. On the other hand, the degree of compressibility was highly reduced by the spheronization time rather than the spheronization rate. This is explained by the high regularly-shaped particles that are less likely to accommodate in the powder bed under the action of an external force as compared to the non-spheronized irregular particles [12].

Flowability is the property that reflects the way in which gravity overcomes the cohesive forces and the interlocking structure of the beads. In general, the flow rate of the samples was high ranging from 13.4 to $16.4 \mathrm{~g} / \mathrm{s}$, independent of the average bead mass. Thus, it is ensured a homogeneous filling of the hard gelatin capsules by using this material. On the other hand, all samples rendered friability values lower than $1.7 \%$ indicating that most bead samples are strong and did not break down or eroded with handling and manipulation, regardless of the spheronization conditions.

Table 1: Effect of spheronization time and frequency on pellet properties

\begin{tabular}{|c|c|c|c|c|c|c|c|c|c|c|c|c|c|c|c|c|c|c|}
\hline Run & $\begin{array}{l}\text { Fre } \\
\text { q } \\
\text { (Hz } \\
\text { ) }\end{array}$ & $\begin{array}{l}\text { ST } \\
\text { (s) }\end{array}$ & $\begin{array}{l}\begin{array}{l}\text { Ar.* } \\
\text { (mm) }\end{array}\end{array}$ & $\begin{array}{l}\begin{array}{l}\text { Per* } \\
\text { (mm) }\end{array}\end{array}$ & $\begin{array}{l}\text { FD* } \\
\text { (mm) }\end{array}$ & Cir* & $\begin{array}{l}\mathbf{A R}^{*} \\
\end{array}$ & $\mathbf{R}^{*}$ & Sol* & $\begin{array}{l}\mathrm{Y} \\
\text { (\%) }\end{array}$ & $\begin{array}{l}\mathrm{BD} \\
\left(\mathrm{g} / \mathrm{m}^{3}\right)\end{array}$ & $\begin{array}{l}\text { TD } \\
(\mathrm{g} / \mathrm{cm})\end{array}$ & $\begin{array}{l}\varepsilon \\
\text { (\%) }\end{array}$ & $\begin{array}{l}\mathrm{M} \\
\text { (mg) }\end{array}$ & $\begin{array}{l}\mathrm{FR}^{*} \\
(\mathrm{~g} / \mathrm{s})\end{array}$ & $\begin{array}{l}\mathrm{Fr} \\
\text { (\%) }\end{array}$ & $\begin{array}{l}\text { MC } \\
\text { (\%) }\end{array}$ & Comp(\%) \\
\hline 1 & 6 & 30 & $\begin{array}{l}0.46 \pm \\
0.19\end{array}$ & $2.78 \pm 0.84$ & $\begin{array}{l}0.98 \pm 0.2 \\
8\end{array}$ & $\begin{array}{l}0.75 \pm 0.1 \\
4\end{array}$ & $\begin{array}{l}0.63 \pm 0.1 \\
8\end{array}$ & $\begin{array}{l}0.67 \pm \\
0.17\end{array}$ & $0.89 \pm 0.06$ & 37.6 & 0.42 & 0.47 & 72.9 & 0.90 & $15.2 \pm 1.7$ & 0.77 & 7.2 & 11.9 \\
\hline 2 & 6 & 120 & $\begin{array}{l}0.95 \pm \\
0.25\end{array}$ & $3.71 \pm 0.66$ & $\begin{array}{l}1.31 \pm 0.2 \\
5\end{array}$ & $\begin{array}{l}0.86 \pm 0.0 \\
7\end{array}$ & $\begin{array}{l}0.75 \pm 0.1 \\
7\end{array}$ & $\begin{array}{l}0.77 \pm \\
0.11\end{array}$ & $0.93 \pm 0.05$ & 60.3 & 0.43 & 0.51 & 72.2 & 0.47 & $15.0 \pm 1.7$ & 0.15 & 7.1 & 18.6 \\
\hline 3 & 6 & 480 & $\begin{array}{l}0.57 \pm \\
0.24\end{array}$ & $2.83 \pm 0.67$ & $\begin{array}{l}0.97 \pm 0.2 \\
3\end{array}$ & $\begin{array}{l}0.86 \pm 0.0 \\
8\end{array}$ & $\begin{array}{l}0.80 \pm 0.1 \\
5\end{array}$ & $\begin{array}{l}0.82 \pm \\
0.11\end{array}$ & $0.93 \pm 0.05$ & 40.1 & 0.52 & 0.55 & 66.5 & 1.14 & $16.4 \pm 0.8$ & 0.61 & 8.7 & 5.8 \\
\hline 4 & 9 & 30 & $\begin{array}{l}0.82 \pm \\
0.32\end{array}$ & $3.64 \pm 0.70$ & $\begin{array}{l}1.42 \pm 0.2 \\
6\end{array}$ & $\begin{array}{l}0.75 \pm 0.0 \\
9\end{array}$ & $\begin{array}{l}0.50 \pm 0.1 \\
2\end{array}$ & $\begin{array}{l}0.53 \pm \\
0.12\end{array}$ & $0.89 \pm 0.03$ & 43.7 & 0.43 & 0.52 & 72.2 & 0.45 & $15.7 \pm 2.0$ & 1.53 & 7.2 & 20.9 \\
\hline 5 & 9 & 120 & $\begin{array}{l}0.80 \pm \\
0.33\end{array}$ & $3.64 \pm 0.91$ & $\begin{array}{l}1.36 \pm 0.2 \\
6\end{array}$ & $\begin{array}{l}0.74 \pm 0.1 \\
3\end{array}$ & $\begin{array}{l}0.55 \pm 0.1 \\
5\end{array}$ & $\begin{array}{l}0.59 \pm \\
0.15\end{array}$ & $0.89 \pm 0.05$ & 32.8 & 0.53 & 0.59 & 65.8 & 2.32 & $14.6 \pm 0.0$ & 1.69 & 7.6 & 11.3 \\
\hline 6 & 9 & 480 & $\begin{array}{l}0.46 \pm \\
0.23\end{array}$ & $2.71 \pm 0.88$ & $\begin{array}{l}1.04 \pm 0.3 \\
3\end{array}$ & $\begin{array}{l}0.79 \pm 0.1 \\
3\end{array}$ & $\begin{array}{l}0.56 \pm 0.1 \\
7\end{array}$ & $\begin{array}{l}0.61 \pm \\
0.14\end{array}$ & $0.89 \pm 0.04$ & 38.3 & 0.51 & 0.57 & 67.1 & 0.22 & $14.5 \pm 0.0$ & 0.31 & 7.2 & 11.8 \\
\hline 7 & 12 & 30 & $\begin{array}{l}0.92 \pm \\
0.29\end{array}$ & $3.70 \pm 0.61$ & $\begin{array}{l}1.35 \pm 0.2 \\
3\end{array}$ & $\begin{array}{l}0.83 \pm 0.0 \\
7\end{array}$ & $\begin{array}{l}0.67 \pm 0.1 \\
6\end{array}$ & $\begin{array}{l}0.70 \pm \\
0.13\end{array}$ & $0.91 \pm 0.04$ & 57.3 & 0.40 & 0.50 & 74.2 & 0.13 & $14.2 \pm 1.2$ & 0.46 & 6.3 & 25.0 \\
\hline 8 & 12 & 120 & $\begin{array}{l}0.49 \pm \\
0.24\end{array}$ & $2.73 \pm 0.85$ & $\begin{array}{l}1.00 \pm 0.3 \\
1\end{array}$ & $\begin{array}{l}0.82 \pm 0.1 \\
3\end{array}$ & $\begin{array}{l}0.66 \pm 0.2 \\
2\end{array}$ & $\begin{array}{l}0.70 \pm \\
0.16\end{array}$ & $0.89 \pm 0.04$ & 62.4 & 0.53 & 0.60 & 65.8 & 19.74 & $13.4 \pm 0.5$ & 0.31 & 6.3 & 13.2 \\
\hline 9 & 12 & 480 & $\begin{array}{l}0.51 \pm \\
0.25\end{array}$ & $2.97 \pm 0.97$ & $2_{2}^{1.07 \pm 0.3}$ & $\begin{array}{l}0.73 \pm 0.1 \\
3\end{array}$ & $\begin{array}{l}0.63 \pm 0.1 \\
8\end{array}$ & $\begin{array}{l}0.67 \pm \\
0.15\end{array}$ & $0.88 \pm 0.04$ & 53.9 & 0.56 & 0.60 & 63.9 & 23.19 & $13.4 \pm 1.1$ & 0.15 & 6.1 & 7.1 \\
\hline
\end{tabular}

Freq: Frequency, ST: spheronization time, Ar: Area, Per: perimeter, FD: Feret diameter, Cir: circularity, AR: aspect ratio, R: roundness, Sol: solidity, Y: yield, BD: bulk density, TD: tap density, ع: porosity, M: mass, FR: flow rate, Fr: Friability, MC: moisture content, Comp: compressibility, ${ }^{*}$ data givenin mean \pm SD of 650 counts

A constant plate diameter of $30 \mathrm{~cm}$ was employed at spheronization rates of 6,9 and $12 \mathrm{~Hz}$ which are equivalent to 360,540 and 720 $\mathrm{rpm}$ and peripheral velocities of 566, 848.2 and $1131 \mathrm{~cm} / \mathrm{s}$, respectively.

The spheronization time varied from 30 to 480 s (fig. 2). The quadratic models indicate that highly spherical pellets indicated by the values of shape descriptors (i.e., circularity, roundness, aspect ratio and solidity) were obtained at $12 \mathrm{~Hz}$ and $\sim 240 \mathrm{~s}$ or $6 \mathrm{~Hz}$ and 480 s. Other researchers have found a rotational speed in the range between 200 and $400 \mathrm{rpm}$ and prolonged residence times as suitable to obtain spherical beads [13]. However, another study reported $420 \mathrm{~cm} / \mathrm{s}$ as the optimal speed employing a small plate spheronizer $(<20 \mathrm{~cm}$ diam) for MCCI [14].

The fig. 3 shows the response surface plots of the beads. No major changes are observed for the bead area, whereas the combination of a large spheronization rate $(12 \mathrm{~Hz})$ and a moderate residence time of $\sim 300 \mathrm{~s}$ was desirable for the development of bigger beads. Conversely, a large rate rather than the residence time was crucial for the formation of large beads with a high product yield. In fact, the use of low rates rendered low product yields due to the loss of sample that fell down at the gap between the edge of the rotating plate and the chamber wall. 
A

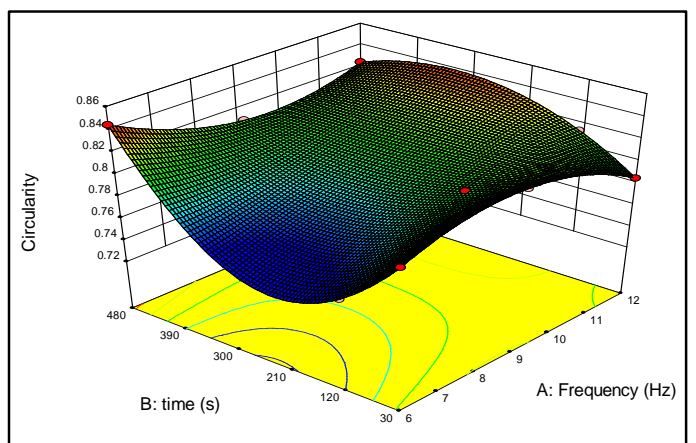

$\operatorname{ArcSin}(\operatorname{Sqrt}(\mathrm{Cir}))=+1.1+0.06 * \mathrm{~A}-0.011^{*} \mathrm{~B}+3.6 \times 10^{-3 *} \mathrm{~A}^{*} \mathrm{~B}-1.27 \times 10$ ${ }^{3 *} A^{2}+0.033^{*} B^{2}+0.035^{*} A^{2 *} B-0.077^{*} A^{*} B^{2} r^{2}=0.9996$

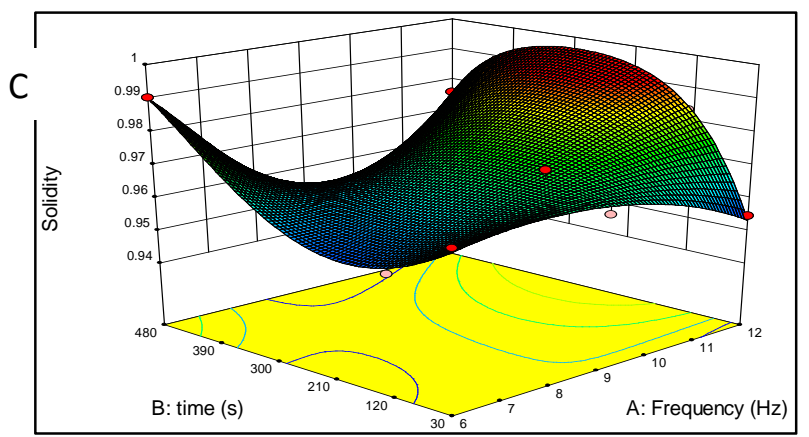

$\operatorname{ArcSin}(\operatorname{Sqrt}(\mathrm{Sol}))=+1.40+0.072 * \mathrm{~A}-0.02 * \mathrm{~B}+2.244 \times 10^{-4 *} \mathrm{~A}^{*} \mathrm{~B}+0.034 * \mathrm{~A}^{2}$ $0.033^{*} \mathrm{~B}^{2}+0.060^{*} \mathrm{~A}^{2} * \mathrm{~B}-0.10^{*} \mathrm{~A}^{*} \mathrm{~B}^{2} \mathrm{r}^{2}=0.9882$
B

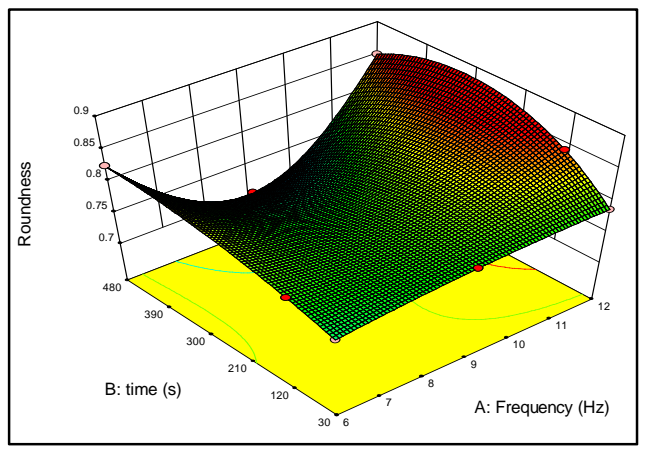

$\operatorname{ArcSin}(\operatorname{Sqrt}($ Round) $)=+1.09+0.049 * \mathrm{~A}-0.045 * \mathrm{~B}+4.659 \times 10$ ${ }^{3 *} \mathrm{~A}^{*} \mathrm{~B}+\mathbf{0 . 0 7 6} \mathrm{A}^{2}-0.053^{*} \mathrm{~B}^{2}+0.090^{*} \mathrm{~A}^{2 *} \mathrm{~B}-0.037^{*} \mathrm{~A}^{*} \mathrm{~B}^{2} \mathrm{r}^{2}=1.0000$

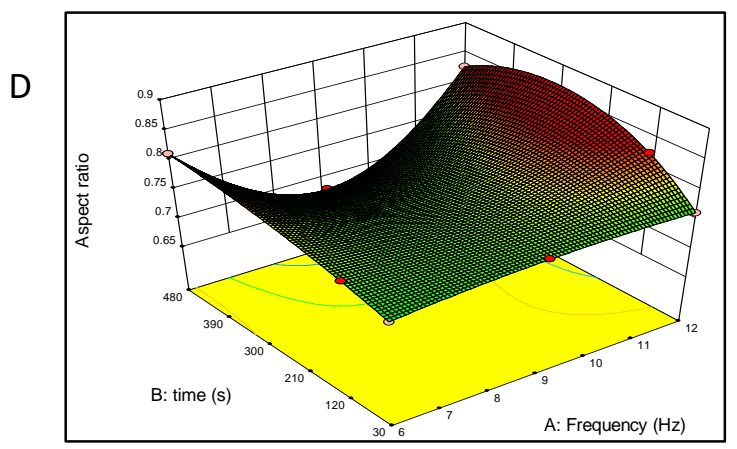

$\operatorname{ArcSin}(\operatorname{Sqrt}(\mathrm{AR}))=+1.07+0.047 * \mathrm{~A}-0.048 * \mathrm{~B}+3.693 \times 10^{-3 *} * \mathrm{~A}^{*}$ $\mathrm{B}+0.075 * \mathrm{~A}^{2}-0.054 * \mathrm{~B}^{2}+0.091^{*} \mathrm{~A}^{2} * \mathrm{~B}-0.042^{*} \mathrm{~A}^{*} \mathrm{~B}^{2} \mathrm{r}^{2}=0.9998$

Fig. 2: Response surface plots of size descriptors and pellets yield. A: area, B: perimeter, C: Feret diameter, D: yield

A

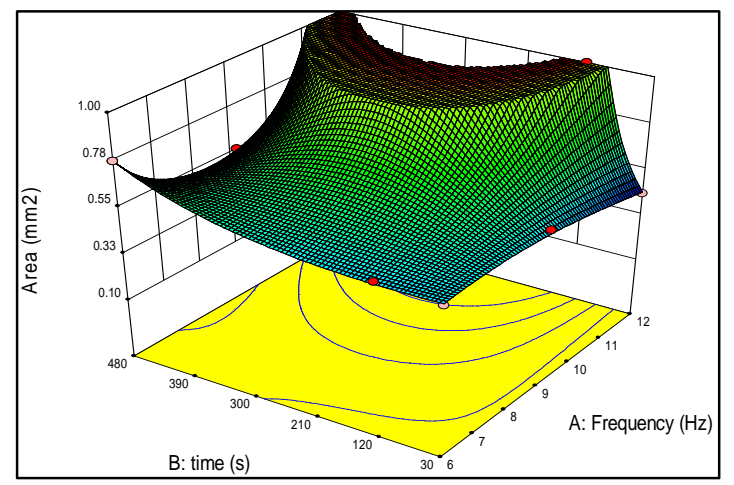

$1 /($ Area $)=+0.86-1.28 * A-0.095 * B-0.43 * A * B-0.38 * A^{2}+1.03 * B^{2}-$ $0.61 * A^{2 *} B+1.23 * A * B^{2} r^{2}=0.9956$

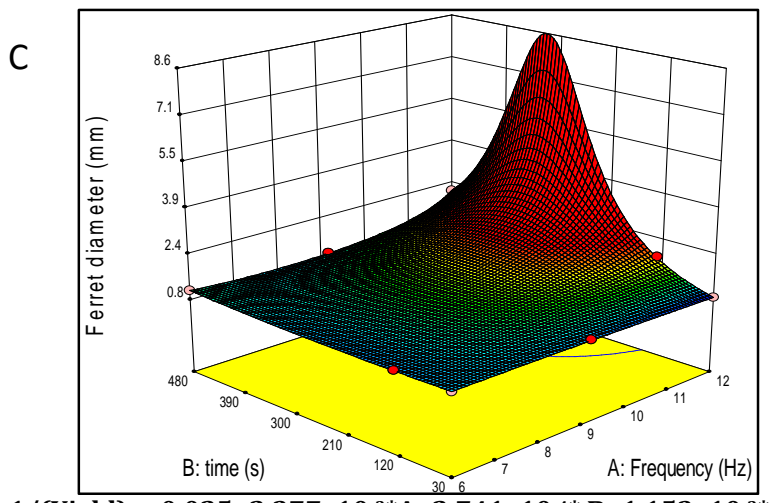

$1 /($ Yield $)=+0.025+2.377 \times 10^{-3 *} \mathrm{~A}+2.741 \times 10^{-4 *} \mathrm{~B}+1.153 \times 10^{-3 *} \mathrm{~A}^{*} \mathrm{~B}-$ $6.514 \times 10^{-3 *} A^{2}+2.541 \times 10^{-3 *} B^{2}-6.688 \times 10^{-3 *} A^{*} B^{2} r^{2}=0.9949$
B

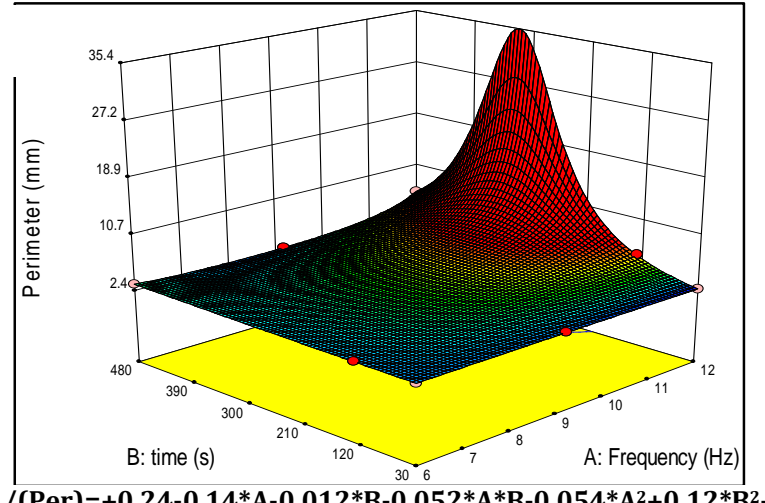

$1 /($ Per $)=+0.24-0.14 * A-0.012 * B-0.052 * A * B-0.054 * A{ }^{2}+0.12 * B{ }^{2}-$ $0.066 * A^{2 *} B+0.12 * A^{*} B^{2} r^{2}=0.9958$

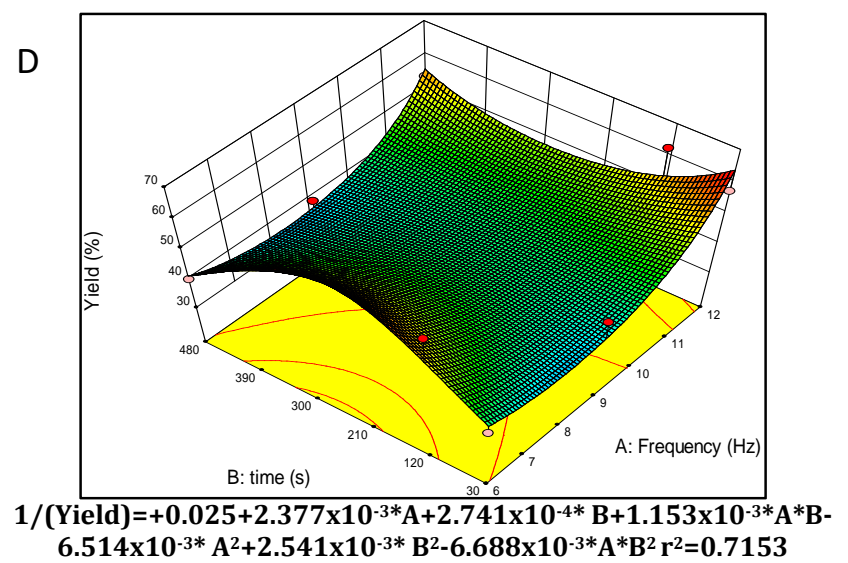

Fig. 3: Response surface plots of shape descriptors of pellets 
The optimization run was obtained from the grid search of the surface plots based on the models obtained for each response. In this case, it was desirable to have conditions to produce the best morphology. That is, the highest roundness, circularity, solidity and aspect ratio, whereas having the lowest particle size. All other conditions were not restricted and remained in the data set range.
The predicted best operational conditions satisfying the previously mentioned conditions was a rate of $6 \mathrm{~Hz}$ and residence time of $480 \mathrm{~s}$ and rendered a desirability of 0.9 (fig. 4). In this case, the predicted values of the area, perimeter, circularity, Feret diameter, product yield, roundness, solidity and aspect ratio were $0.78 \mathrm{~mm}, 3.4 \mathrm{~mm}$, $0.84,1.1 \mathrm{~mm}, 41.4 \%, 0.83,0.99$, and 0.81 , respectively.

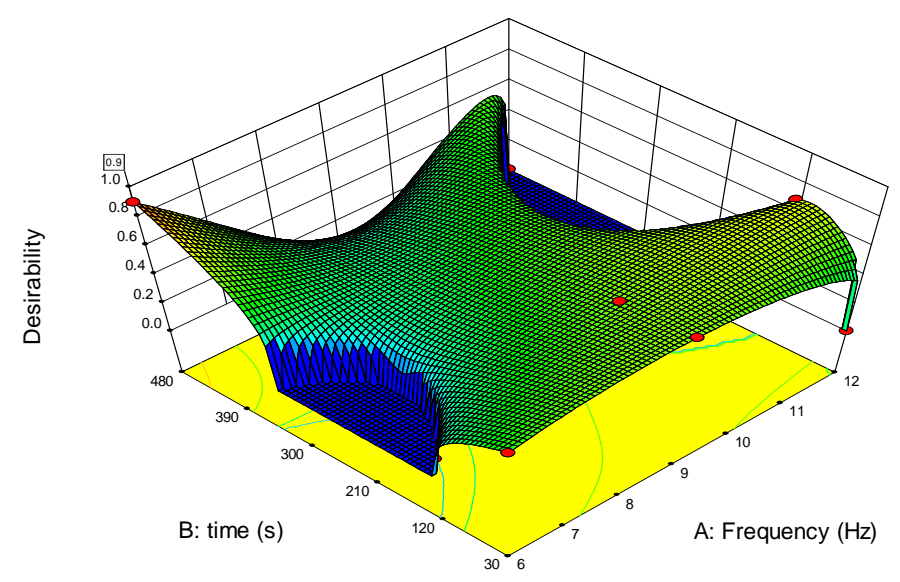

Fig. 4: Response surface plot showing the optimal operational conditions

\section{Effect of wetting level on beads properties}

Fig. 5 and table 2 show the effect of wetting on pellet properties. The wetting level was an important parameter for the pelletization process because it awarded plasticity to the MCCII mass so that it could be extruded and spheronized. During wet-massing, coalescence and growth of the MCCII particles were induced due to the formation of massive and strong hydrogen bonding interactions [15]. In this scenario, water molecules provided the required plasticity to the MCCII mass so a permanent bonding occurs.

The digital analysis included an assessment of the roundness, solidity, circularity and aspect ratio the vertices and edges of the pellets. Descriptors such as circularity, roundness, and aspect ratio are related to the pellet shape. The aspect ratio describes the ratio between the width and length of the pellet. This characteristic is related to the elongation of the particle, whereas sphericity is described by the value of roundness. An aspect ratio of 0.9 can be considered as nearly spherical. Results indicate that all shape descriptors increased in magnitude with increasing moisture levels, especially with wetting levels of 100 and $125 \%$ and a value close to one for these dimensional factors indicates that the particle shape is almost spherical. Thus, at high wetting levels, the pellets changed from an irregular shape to oblong and spherical geometry. Further,

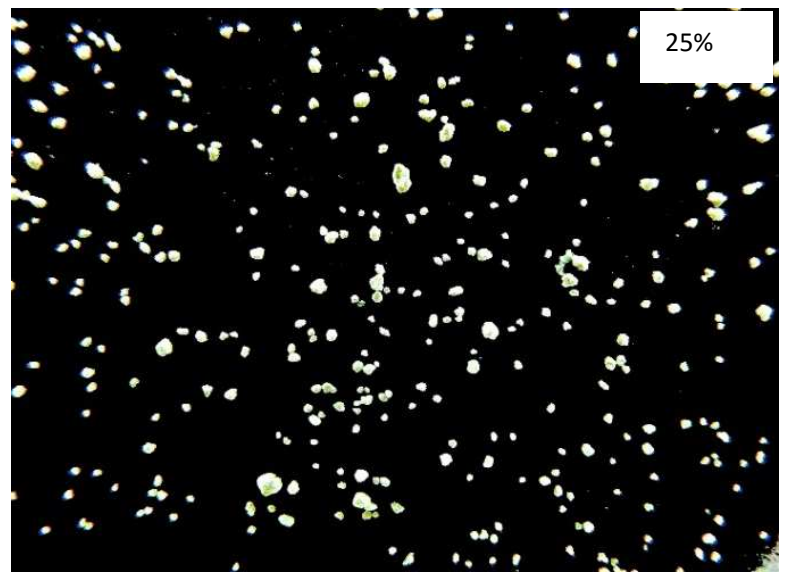

there was a direct relationship between the moisture level and the resulting area, diameter and perimeter of the pellets.

In general, a large wetting degree $(>100 \%)$ was related to a large increase in pellet size, whereas a low wetting degree $(\leq 50 \%)$ made the MCCII mass less cohesive and more susceptible to be blown-off the rotating plate and hence, the spheronization yield was reduced and the quality of the produced pellets became unacceptable. Thus, at low wetting levels a lot of dusty particles were introduced during the spheronization process that was be reflected on (i) a large yield of fines due to attrition of the extrudate which subsequently fell down between the edge of the spheronizer plate and the chamber wall; or (ii) a great formation of an extrudate which although was reduced in length, remained as cylindrical or 'non-rounded' pellets. On the other hand, when the moisture content was larger than the certain upper limit $(125 \% \mathrm{w} / \mathrm{w})$ an overweighed mass and agglomeration of individual pellets occurred due to the accumulation of excessive water at the pellet surface. Beyond this value, a very sticky dough was produced which not pass through the \# 20 mesh sieved. As a result, the spheronization process became very difficult since this wet mass was not brittle enough for disintegration. Further, the excessive wetting and hence, plasticity made the material too tacky resulting in the formation of extremely large pellets under the effect of the centrifugal force.

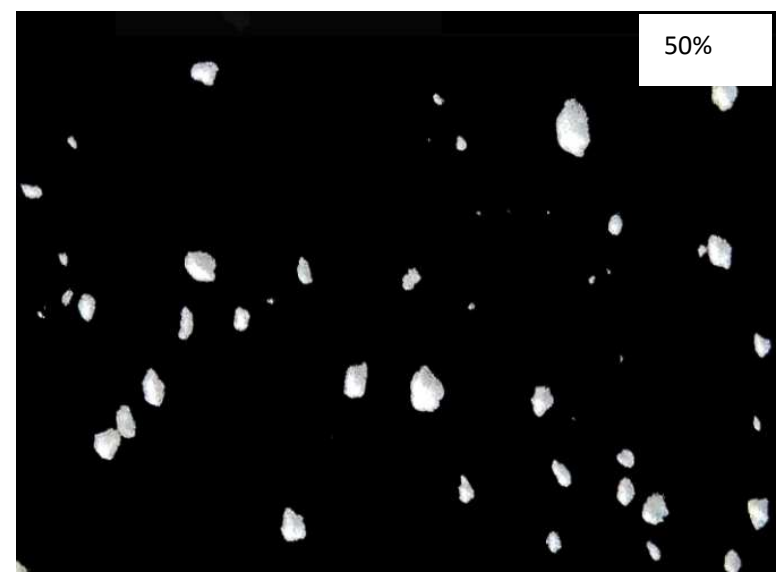



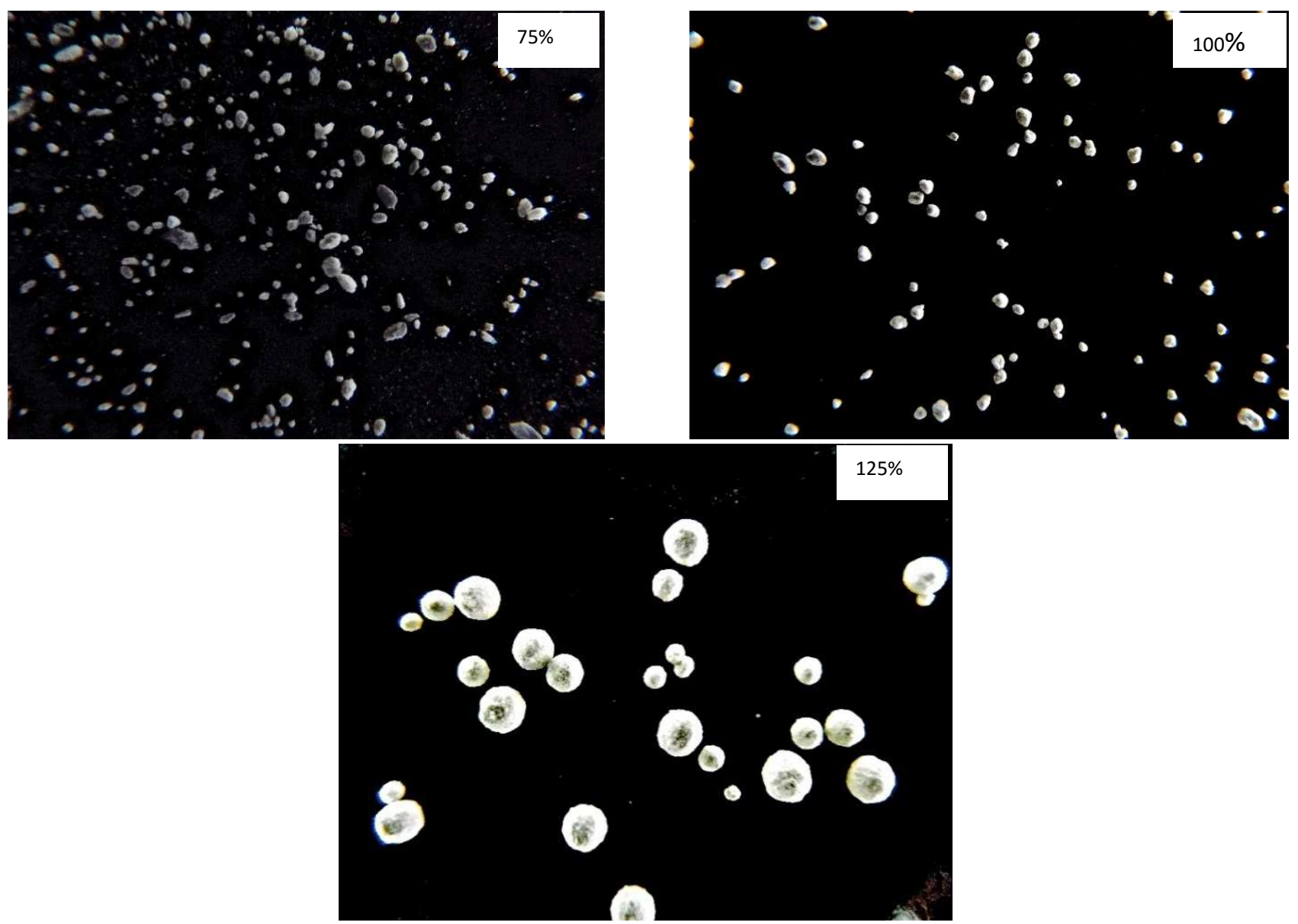

Fig. 5: Micro pictures of beads produced under different wetting levels

The total porosity and surface roughness of the beads decreased as the wetting level increased. These factors, in turn, depended on the particle size. For instance, large beads presented a smoother, nonporous surface and a more spherical shape, whereas smaller beads presented a predominant rougher surface.

The bead area is defined as the surface area of a cylinder having the same radius and the height corresponding to the diameter to that of the sphere, whereas perimeter is defined as the linear distance around a two-dimensional geometry. On the other hand, the Feret diameter is the distance between two parallel tangent planes touching the surface of the bead. A direct relationship was found between the wetting level and size descriptors such as area, perimeter, and Feret diameter. This effect was much more pronounced at high wetting levels $(125 \%)$. On the other hand, it was observed a steady increase of the magnitude of the shape descriptors such roundness, solidity and aspect ratio with high wetting levels. This indicates the formation of more regularlyshaped particles. This finding was more evident at a $125 \%$ wetting level, $6 \mathrm{~Hz}$, and 480s due to the extensive formation of hydrogen bonds facilitating the agglomeration, plastic shaping and pellet growth.

Flowability did not increase with the wetting level indicating that gravity rather than morphology and perhaps size played a major role on bead flow. Only particles with sizes $<250 \mu \mathrm{m}$ having more irregular shape were prompt for the formation of particle interlocking, rough surfaces and indentations.

A high wetting level $(\geq 100 \%)$ improved yield, pellet mass, and densification, but lowered the friability, compressibility and porosity of pellets. This indicates that wettability was inversely correlated to friability and that bead strength increased with size. However, bead mass showed a direct relationship with the wetting level. The opposite occurred for compressibility and porosity which decreased as the amount of added water increased. In fact, there was an inverse relationship between compressibility and densification. This is explained by the high packing ability that samples gained once they grew in size reducing their total porosity and became less compressible.

\section{Effect of loading on beads properties}

Fig. 6 and table 3 show the effect of sample load on bead properties. The rotating plate must have an appropriate load to allow for "chopping" of the extrudate after which the fragments move in a torroidal motion. Surprisingly, the smaller the sample load is, the better is the performance of the spheronization process. Thus, the magnitude of size descriptors decreased whereas the values of shape descriptors and flowability appear to remain unchanged when sample loads increased. On the other hand, friability as an indirect indicator of pellet strength remained under $1 \%$. Further, densification and bead mass seem to decrease with high loads, whereas compressibility and porosity increased. This phenomenon could be attributed mainly to the size effect gained by the loading process. In this case, higher loads would proportionally require higher spheronization rates and residence times to have a higher probability for the formation of sufficient particle collisions or frictional forces to round-off edges and imperfections of the particles and in turn, allowed for a larger bead growth. Previous studies conducted on MCCI demonstrated that small plates require higher speeds for an optimal performance. For instance, $800 \mathrm{rpm}$ might be required for a plate diameter of $21.2 \mathrm{~cm}$ with an optimal load of $300 \mathrm{~g}$. Further, the production yield was highly affected by high samples loads (i.e., $150 \mathrm{~g}$ ) since large residence times caused a massive loss of fine powder on the gap between the rotating plate and the chamber wall due to the centrifugal action. 
Table 2: Effect of wetting level on bead properties

\begin{tabular}{|c|c|c|c|c|c|c|c|c|c|c|c|c|c|c|c|c|}
\hline Run & $\begin{array}{l}\text { Wetting } \\
\text { level } \\
\text { (\%w/w, db) }\end{array}$ & $\begin{array}{l}\mathrm{Ar}^{*} \\
\left(\mathrm{~mm}^{2}\right)\end{array}$ & $\begin{array}{l}\begin{array}{l}\text { Per* } \\
\text { (mm) }\end{array}\end{array}$ & $\begin{array}{l}\text { FD* }^{*} \\
(\mathrm{~mm})\end{array}$ & Circ* & $\mathbf{R}^{*}$ & Sol* & $\mathbf{A R}^{*}$ & $\begin{array}{l}\mathrm{Fr} \\
(\%)\end{array}$ & $\begin{array}{l}\mathrm{FR} \\
(\mathrm{g} / \mathrm{s}) \\
\mathrm{n}=5\end{array}$ & $\begin{array}{l}\mathrm{M} \\
\text { (mg) }\end{array}$ & $\begin{array}{l}\text { BD } \\
\left(\mathrm{g} / \mathrm{cm}^{3}\right)\end{array}$ & $\begin{array}{l}\text { TD } \\
\left(\mathrm{g} / \mathrm{cm}^{3}\right)\end{array}$ & $\begin{array}{l}Y \\
\text { (\%) }\end{array}$ & $\begin{array}{l}\varepsilon \\
\text { (\%) }\end{array}$ & $\begin{array}{l}\text { Comp } \\
\text { (\%) }\end{array}$ \\
\hline$\overline{\mathrm{E} 1}$ & 25 & $\begin{array}{l}0.14 \pm \\
0.08\end{array}$ & $\begin{array}{l}1.48 \pm \\
0.56\end{array}$ & $\begin{array}{l}0.52 \pm \\
0.16\end{array}$ & $\begin{array}{l}0.76 \pm \\
0.13\end{array}$ & $\begin{array}{l}0.72 \pm \\
0.15\end{array}$ & $0.89 \pm 0.06$ & $\begin{array}{l}0.69 \pm 0.1 \\
1\end{array}$ & 0.6 & $\begin{array}{l}15.6 \\
\pm 0.8\end{array}$ & 0.1 & 0.28 & 0.37 & 0.73 & 82 & 24.3 \\
\hline E2 & 50 & $\begin{array}{l}0.29 \pm \\
0.03\end{array}$ & $\begin{array}{l}2.04 \pm \\
0.5\end{array}$ & $\begin{array}{l}0.72 \pm \\
0.3\end{array}$ & $\begin{array}{l}0.76 \pm \\
0.13\end{array}$ & $\begin{array}{l}0.72 \pm \\
0.15\end{array}$ & $0.90 \pm 0.05$ & $\begin{array}{l}0.68 \pm 0.1 \\
1\end{array}$ & 0.9 & $\begin{array}{l}15.5 \\
\pm 0.0\end{array}$ & 0.1 & 0.30 & 0.39 & 1.0 & 80.7 & 23.1 \\
\hline E3 & 75 & $\begin{array}{l}0.33 \pm \\
0.12\end{array}$ & $\begin{array}{l}2.33 \pm \\
0.27\end{array}$ & $\begin{array}{l}0.74 \pm \\
0.23\end{array}$ & $\begin{array}{l}0.73 \pm \\
0.1\end{array}$ & $\begin{array}{l}0.81 \pm \\
0.12\end{array}$ & $0.93 \pm 0.05$ & $\begin{array}{l}0.79 \pm 0.1 \\
2\end{array}$ & 3.3 & $\begin{array}{l}14.4 \\
\pm 1.2\end{array}$ & 0.5 & 0.34 & 0.41 & 17.0 & 78.1 & 17.1 \\
\hline E4 & 100 & $\begin{array}{l}0.34 \pm \\
0.12\end{array}$ & $\begin{array}{l}2.14 \pm \\
0.35\end{array}$ & $0.77 \pm 0.24$ & $\begin{array}{l}0.89 \pm \\
0.09\end{array}$ & $\begin{array}{l}0.79 \pm \\
0.12\end{array}$ & $0.90 \pm 0.03$ & $\begin{array}{l}0.77 \pm 0.1 \\
1\end{array}$ & 0.6 & $\begin{array}{l}14.3 \\
\pm 0.5\end{array}$ & 1.4 & 0.43 & 0.47 & 40.1 & 72.3 & 8.5 \\
\hline E5 & 125 & $10.48 \pm 3.72$ & $12.42 \pm 2.39$ & $3.80 \pm 0.92$ & $\begin{array}{l}0.77 \pm \\
0.21 \\
\end{array}$ & $\begin{array}{l}0.86 \pm \\
0.17\end{array}$ & $0.95 \pm 0.12$ & $\begin{array}{l}0.78 \pm 0.2 \\
3\end{array}$ & 0.9 & $\begin{array}{r}12.9 \\
\pm 1.1 \\
\end{array}$ & 16.0 & 0.41 & 0.45 & 62.1 & 73.5 & 8.9 \\
\hline
\end{tabular}

Ar: Area, Per: perimeter, FD: Feret diameter, Cir: circularity, AR: aspect ratio, R: roundness, Sol: solidity, Y: yield, BD: bulk density, TD: tap density, $\varepsilon$ : porosity, M: mass, FR: flow rate, Fr: Friability, MC: moisture content, db: dry basis, Comp: compressibility. Operational conditions of $6 \mathrm{~Hz}$ and $480 \mathrm{~s}$, *data givenin mean \pm SD of 650 counts
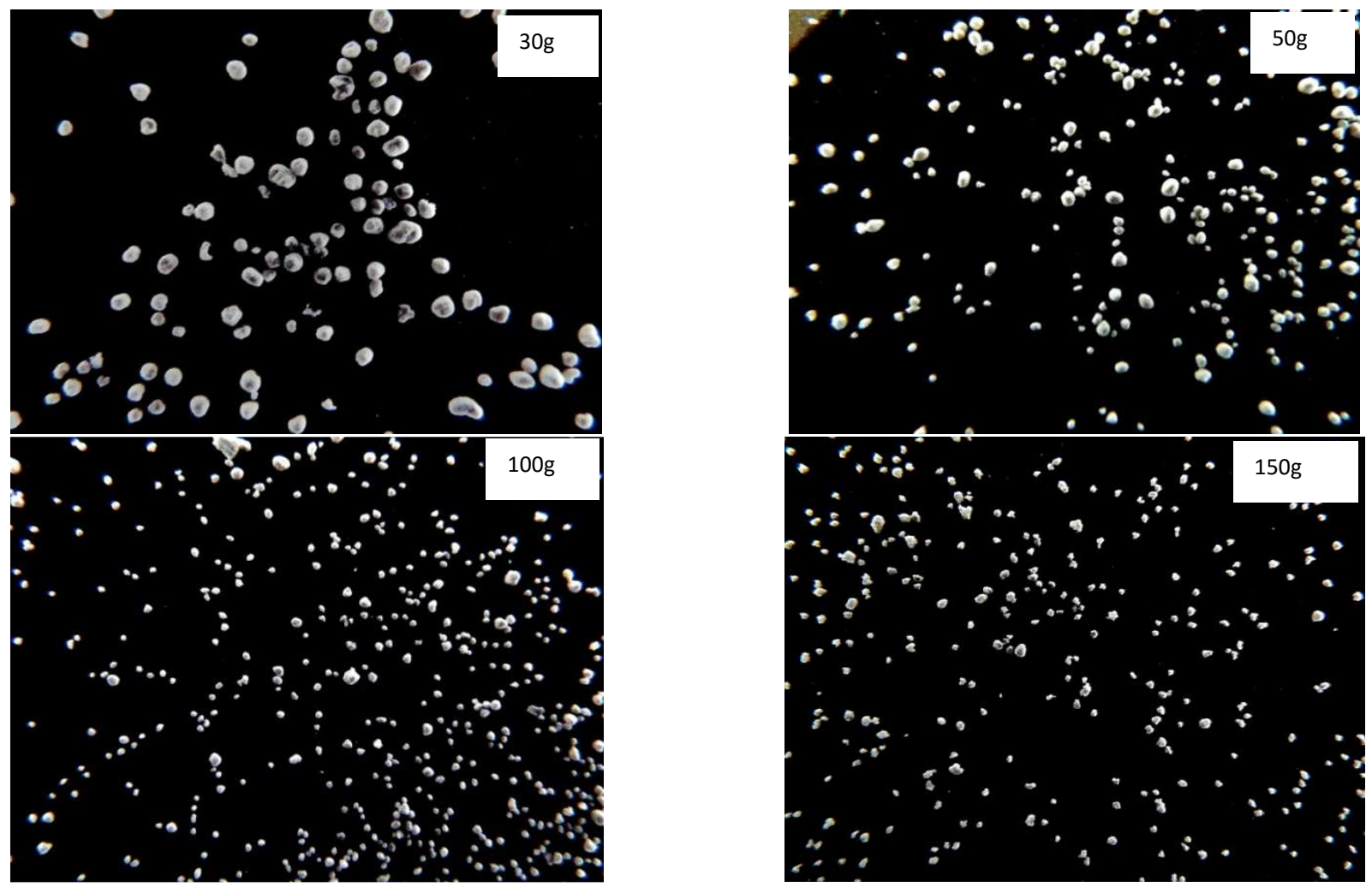

Fig. 6: Micro pictures of beads produced under different chamber loads

Table 3: Effect of MCCII load on pellet properties

\begin{tabular}{|c|c|c|c|c|c|c|c|c|c|c|c|c|c|c|c|c|c|}
\hline Run & $\begin{array}{l}\text { Load } \\
\text { (g) }\end{array}$ & $\begin{array}{l}\mathrm{Ar}^{*} \\
(\mathrm{~mm})\end{array}$ & $\begin{array}{l}\text { Per* } \\
\text { (mm) }\end{array}$ & FD* & Cir* & $\mathbf{A R}^{*}$ & $\mathrm{R}^{*}$ & Sol* & $\begin{array}{l}\mathbf{Y} \\
(\%) \\
\end{array}$ & $\begin{array}{l}\mathrm{Fr} \\
(\%)\end{array}$ & \begin{tabular}{|l} 
FR \\
$(\mathrm{g} / \mathrm{s})$
\end{tabular} & $\begin{array}{l}\text { M } \\
\text { (mg) }\end{array}$ & $\begin{array}{l}\text { BD } \\
\left(\mathrm{g} / \mathrm{cm}^{3}\right)\end{array}$ & $\begin{array}{l}\text { TD } \\
\left(\mathrm{g} / \mathrm{cm}^{3}\right)\end{array}$ & $\begin{array}{l}\varepsilon \\
(\%) \\
\end{array}$ & $\begin{array}{l}\text { MC } \\
(\%)\end{array}$ & $\begin{array}{l}\text { Comp } \\
(\%)\end{array}$ \\
\hline E1 & 30 & $0.87 \pm 0.3$ & $\begin{array}{l}3.59 \pm \\
0.8\end{array}$ & $\begin{array}{l}1.24 \pm \\
0.27\end{array}$ & $0.83 \pm 0.1$ & $\begin{array}{l}0.72 \pm 0.1 \\
5\end{array}$ & $0.75 \pm 0.12$ & $\begin{array}{l}0.97 \pm 0.0 \\
7\end{array}$ & 11.7 & 0.39 & 9.4 & 3.8 & 0.48 & 0.52 & 68.9 & 6.3 & 6.7 \\
\hline E2 & 50 & $\begin{array}{l}0.44 \pm \\
0.22\end{array}$ & $\begin{array}{l}2.55 \pm \\
0.61\end{array}$ & $\begin{array}{l}0.87 \pm \\
0.21\end{array}$ & $0.84 \pm 0.07$ & $\begin{array}{l}0.78 \pm 0.1 \\
2\end{array}$ & $0.80 \pm 0.1$ & $\begin{array}{l}0.96 \pm 0.0 \\
5\end{array}$ & 34.4 & 0.05 & 4.5 & 1.7 & 0.47 & 0.53 & 69.8 & 6.8 & 11.2 \\
\hline E3 & 100 & $\begin{array}{l}0.49 \pm \\
0.26\end{array}$ & $\begin{array}{l}2.63 \pm \\
0.69\end{array}$ & $\begin{array}{l}0.91 \pm \\
0.24\end{array}$ & $0.86 \pm 0.07$ & $\begin{array}{l}0.77 \pm 0.2 \\
4\end{array}$ & $0.79 \pm 0.11$ & $\begin{array}{l}0.95 \pm 0.0 \\
5\end{array}$ & 27.1 & 0.0 & 8.8 & 1.9 & 0.46 & 0.52 & 70.3 & 7.3 & 12 \\
\hline E4 & 150 & $\begin{array}{l}0.22 \pm \\
0.12 \\
\end{array}$ & $\begin{array}{l}1.84 \pm \\
0.54 \\
\end{array}$ & $\begin{array}{l}0.64 \pm \\
0.18\end{array}$ & $0.78 \pm 0.1$ & $\begin{array}{l}0.70 \pm 0.3 \\
3\end{array}$ & $0.73 \pm 0.13$ & $\begin{array}{l}0.92 \pm 0.0 \\
5\end{array}$ & 2.2 & 0.22 & 7.6 & 0.8 & 0.32 & 0.4 & 79.7 & 7.4 & 19.9 \\
\hline
\end{tabular}

Ar: Area, Per: perimeter, FD: Feret diameter, Cir: circularity, AR: aspect ratio, R: roundness, Sol: solidity, Y: yield, BD: bulk density, TD: tap density, $\varepsilon$ : porosity, M: mass, FR: flow rate, Fr: Friability, MC: moisture content, Comp: compressibility. Operational conditions of $6 \mathrm{~Hz}$, $480 \mathrm{~s}$ and $100 \%$ wetting

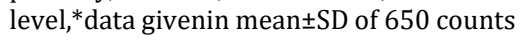

\section{CONCLUSION}

The combination of processing variables such as low spheronization rates $(6 \mathrm{~Hz}), 30 \mathrm{~g}$ load, wetting level of $100 \%$ and high residence times (480 s) were chosen as optimal to render beads with the best morphology, small particle size and the best performance. At these conditions, beads presented a spherical shape, good flow and optimal dispensability. Further, a wetting level between 100 and $125 \%$ was optimal to award the sufficient plasticity to the MCCII mass so it could be spheronized. On the other hand, high sample loads $(>50 \mathrm{~g})$ caused an insufficient particle-particle or particle-plate interaction, which resulted in smaller pellets having low densities and irregular shapes.

\section{ACKNOWLEDGEMENT}

Both authors performed the experimental runs and analytical tests. Dr. John Rojas was in charge of writing the text and executed the pertinent corrections. The authors thank Mr. Cesar Londoño and Juan Castaño for their technical assistance with the preliminary studies.

\section{CONFLICT OF INTERESTS}

Declared none 


\section{REFERENCES}

1. Obernberger I, Thek G. The pellet handbook: The production and thermal utilization of biomass pellets. London: Earthscan; 2010. p. 1-593.

2. Lavanya K. Pelletization technology: a quick review. Int J Pharm Sci Res 2011;2:1337-55.

3. Hileman GA, Upadrashta SM, Neau SH. Drug solubility effects predicting optimum conditions for extrusion and spheronization of pellets. Pharm Dev Technol 1997;2:43-52.

4. Supriya P, Rajni B, Rana AC. Pelletization techniques: a literature review. Int Res J Pharm 2012;3:43-7.

5. Otero F, Luzardo A, Blanco J. Non-MCC materials as extrusionspheronization aids in pellets production. J Drug Delivery Sci Technol 2010;20:303-18.

6. Londono C, Rojas J. Effect of different production variables on the physical properties of pellets prepared by extrusion-spheronization using a multivariate analysis. Thai J Pharm Sci 2017;41:1-7.

7. Kleinebudde $P$, Jumaa $M$, Saleh F. Influence of degree of polymerization on the behaviour of cellulose during homogenization and extrusion/spheronization. AAPS PharmSci 2000;2:1-10.

8. Rojas J, Lopez A, Gamboa Y, Gonzalez C, Montoya F. assessment of processing and polymorphic form on the powder and tabletting properties of microcrystalline cellulose I and II. Chem Pharm Bull 2011;59:603-7.

9. Rojas J, Yepes M, Ciro Y. Viscosity, agglomeration behaviour and tabletting characteristics of cassava starch modulated by wet granulation: a comparative study. In: Molinari F, editor.
Cassava, production, nutritional properties and health effects. New York, U. S. A: Nova; 2014. p. 139-59.

10. Pisek R, Planinsek O, Tus M, Srcic S. Influence of rotational speed and surface of rotating disc on pellets produced by direct rotor pelletization. Pharm Indian 2016;62:312-9.

11. Ketan A, Mehta RO, Gurvinder SR. Extrusion/spheronization as a granulation technique. In: Parikh DM. editor. Handbook of pharmaceutical granulation technology. Taylor and Francis; 2005. p. 333-45.

12. Lovgre K, Lundberg P. Determination of sphericity of pellets prepared by extrusion/spheronization and the impact of some process parameters. Drug Dev Ind Pharm 1989;15:2375-92.

13. Majidi B, Melob J, Fafard M, Ziegler D, Alamdari H. Packing density of irregular shape particles: DEM simulations applied to anode-grade coke aggregates. Adv Powder Technol 2015,261256-62.

14. Newton JM, Chapman SR, Rowe RC. The assessment of the scale-up performance of the extrusion/spheronization process. Int J Pharm 1995;120:95-9.

15. Ketan A, Mehta RO, Gurvinder SR. Extrusion/spheronization as a granulation technique. In: Parikh DM. editor. Handbook of pharmaceutical granulation technology. Taylor and Francis; 2005. p. 333-45.

\section{How to cite this article}

- John Rojas, David Correa. Assessment of the production variables on the pelletization properties of microcrystalline cellulose II (MCCII). Int J Pharm Pharm Sci 2017;9(10):73-80. 